\title{
DISTRIBUIÇÃO DE BIOMPHALARIA TENAGOPHILA E B. OCCIDENTALIS NO ESTADO DE SÃO PAULO (BRASIL)
}

\author{
Horacio Manuel Santana Teles*
}

\begin{abstract}
TELES, H.M.S. Distribuição de Biomphalaria tenagophila e B. occidentalis no Estado de São Paulo (Brasil). Rev. Saúde públ., S. Paulo, 23: 244-53, 1989.

RESUMO: São apresentadas as áreas colonizadas por Biomphalaria tenagophila (d'Orbigny, 1835) e B. occidentalis Paraense, 1981 no Estado de São Paulo (Brasil), destacando que a primeira espécie de planorbídeo é um importante hospedeiro intermediário de Schistosoma mansoni Sambon, 1907. Foi apresentada a distribuição geográfica de $B$. occidentalis pelo fato de esta espécie ter sido, até recentemente, confundida $\operatorname{com} B$. tenagophila. Os dois planorbídeos habitam ambientes límnicos de extensas áreas do território paulista e foram identificados entre 3.160 lotes de bionfalárias coletados de setembro de 1981 a março de 1986, em todos os municípios do Estado. B. tenagophila foi diagnosticada em 1.602 lotes procedentes de 203 municípios e $B$. occidentalis em 255 de 97 municípios. São comentadas as circunstâncias biogeográficas relacionadas com a distribuição das espécies.
\end{abstract}

DESCRITORES: Biomphalaria, crescimento. Esquistossomose mansônica, incidência. Ecologia de vetores.

\section{INTRODUÇÃO}

Os primeiros relatos da ocorrência de Biomphalaria tenagophila (d'Orbigny, 1835) no Estado de São Paulo são imprecisos até a publicação dos estudos de Paraense e Deslances ${ }^{6}$. Também a participação deste planorbídeo na transmissão da esquistossomose foi um assunto inicialmente controverso, definido somente após o encontro de exemplares naturalmente infestados por Schistosoma mansoni Sambon, 1907, no Município de Santos.

Dirimidas as dúvidas sobre a taxonomia e o potencial epidemiológico de $B$. tenagophila, as descobertas de focos envolvendo a espécie foram sucessivas, permitindo a caracterização das áreas endêmicas da Baixada Santista, vales do Ribeira e Paraíba, além dos focos isolados em outros municípios situados fora destas. Tal situação solicitou maiores conhecimentos sobre a distribuição geográfica das espécies de planorbídeos, particularmente daquelas hospedeiras de $S$. mansoni, para o desenvolvimento de um programa de controle da doença. Estes conhecimentos foram alcançados com o trabalho de $\mathrm{Pi}$ za e col. ${ }^{8}$. Os resultados da "Carta Planorbídica do Estado de São Paulo" tiveram grande utilidade até a descrição de $B$. occidentalis Paraense, $1981^{4}$, espécie bastante assemelhada com $B$. tenagophila.

Constatada a ocorrềncia de $B$. occidentalis em São Paulo de Endemias (SUCEN), prontamente conduziu um novo inquérito na malacofauna límnica, cujos dados obtidos com as espécies em pauta são mostrados e analisados no presente trabalho.

\section{MATERIAL E MÉTODOS}

As coletas de caramujos realizadas de setembro de 1981 a março de 1986 abrangeram ambientes límnicos situados nos 572 municípios que compóem o Estado. Nesse período examinaram-se no Laboratório de Malacologia, da SUCEN, 3.160 lotes de bionfalárias, cada um deles formado por um a mais de uma centena de exemplares. Quando possível foram separados 10 exemplares por lote para preservação das conchas e partes moles, estas últimas imersas em líquido de Railliet e Henry. Todo o material estudado faz parte da coleção mantida pela citada instituição.

O diagnóstico específico foi conseguido principalmente com a observação da morfologia do sistema reprodutor das espécies, uma vez que a conquiliologia não acrescenta muito na diferenciação de $B$. tenagophila e $B$. occidentalis.

Para propiciar a padronização dos trabalhos de campo, as equipes da SUCEN visitaram ao menos duas coleções hídricas a cada $100 \mathrm{~km}^{2}$, dando preferência àquelas com residências nas proximidades. Somente a pesquisa em seis coleções hídricas sem coleta de caramujos possibili-

- Superintendência de Controle de Endemias (SUCEN) - Rua Paula Souza, 166 - 01027 - São Paulo, SP - Brasil. 
tou a consideração da "ausência de caramujos" na área.

\section{RESULTADOS}

Dentre os 3.160 lotes, $B$. tenagophila foi identificada em $1.062(33,60 \%)$ e $B$. occidentalis em $255(8,06 \%)$. Levando em conta os municípios que compõem o Estado (572), a primeira espécie aparece em 203 e a segunda em 97, respectivamente, $35,48 \%$ e $16,95 \%$. Estes dados foram extraídos do Anexo, que mostra as espécies diagnosticadas por município e $o$ número de exemplares e criadouros. Ainda no Anexo, estão assinalados os 25 municípios onde ocorrem populações simpátricas, bem como transparece que o número de indivíduos da espécie tenagophila é superior ao de occidentalis.

Quanto à distribuição geográfica de B. tenagophila(Fig. 1), percebe-se que a espécie exibe uma notável concentração de criadouros nas bacias formadas pelos rios Tietê (Alto e Médio), Paraiba do Sul, Ribeira de Iguape e litoral, que incorpora numerosas bacias pequenas e dentríticas entremeadas de manguezais. Os criadouros da espécie rareiam na direção do extremo oeste paulista, não sendo encontrados na área banhada pelo Rio São José dos Dourados, Grande e baixios do Paranapanema. Os limites distributivos extremos para $B$. tenagophila no território paulista estão situados nos criadouros dos municípios de Bebedouro (norte), Cananéia (sul), Bananal (leste) e Caiuá (oeste).

$B$. occcidentalis só não coloniza as áreas litorâneas e do Rio Ribeira de Iguape, distribuindo-se mais uniformemente na grande região delimitada Rio Paraná e baixios do Tietê e Paranapanema (Fig. 2). Ao contrário de $B$. tenagophila, os criadouros de $B$. occidentalis vão escasseando na direção leste.

Comparando as Figs. 1 e 2, é nítido o predomínio de $B$. tenagophila sobre $B$. occidentalis, em termos de extensão das áreas colonizadas no Estado. Esse predomínio também é corroborado pelo número de criadouros habitados pelas espécies e total de exemplares coletados.

\section{COMENTÁRIOS E CONCLUSŌES}

Os resultados divulgados por Piza e col. ${ }^{8}$ apontaram a ocorrência de $B$. tenagophila em 208 municípios, contra os 203 observados no presente. $B$. occidentalis passou despercebida à época. Estes autores reconheceram $B$. tenagophila em 34 municípios onde no momento só se verificou a ocorrência de $B$. occidentalis (Alfredo Marcondes, Álvares Macha-

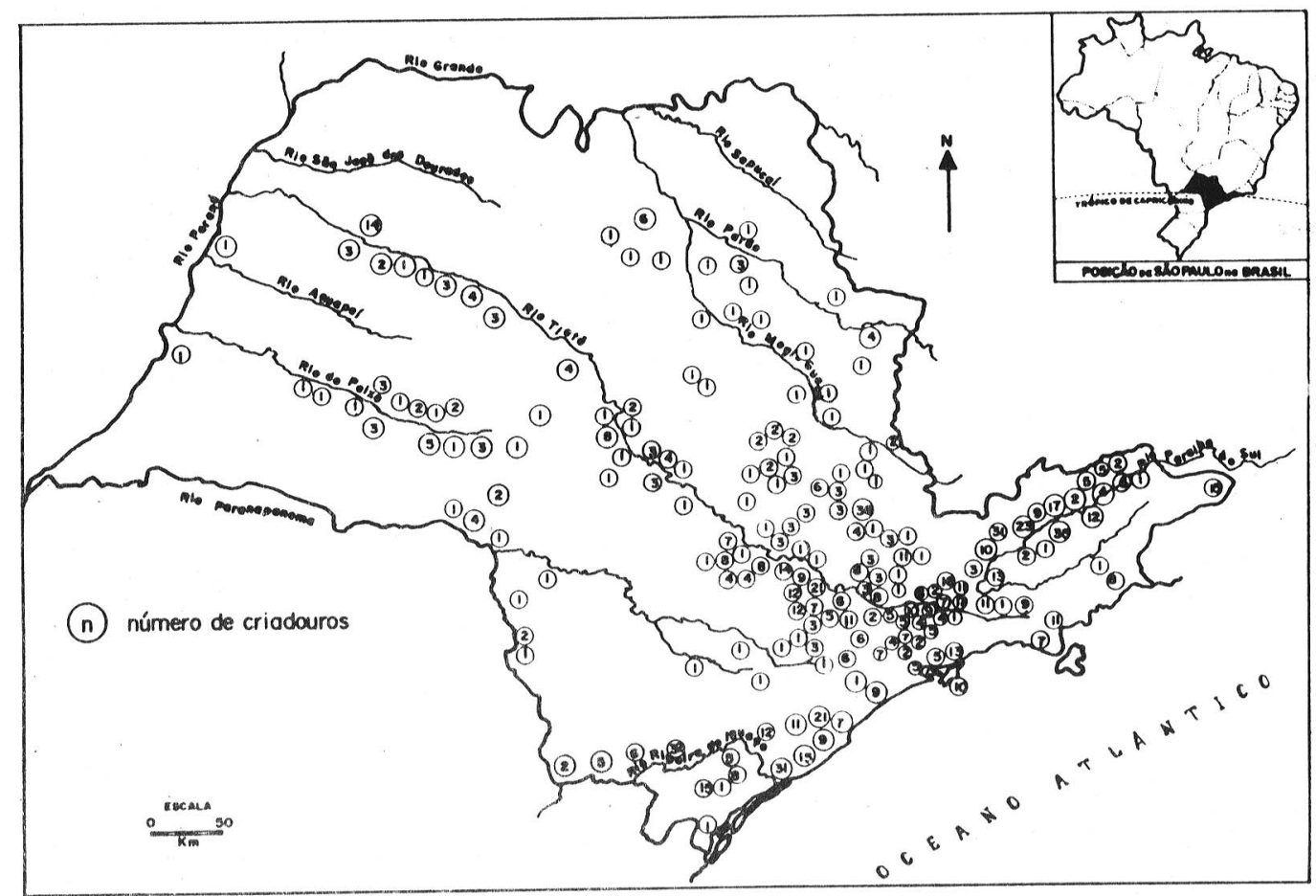

Fig. 1 - Localização dos criadouros de Biomphalaria tenagophila descobertos por município do Estado de São Paulo (Brasil) de setembro de 1981 a março de 1986. 


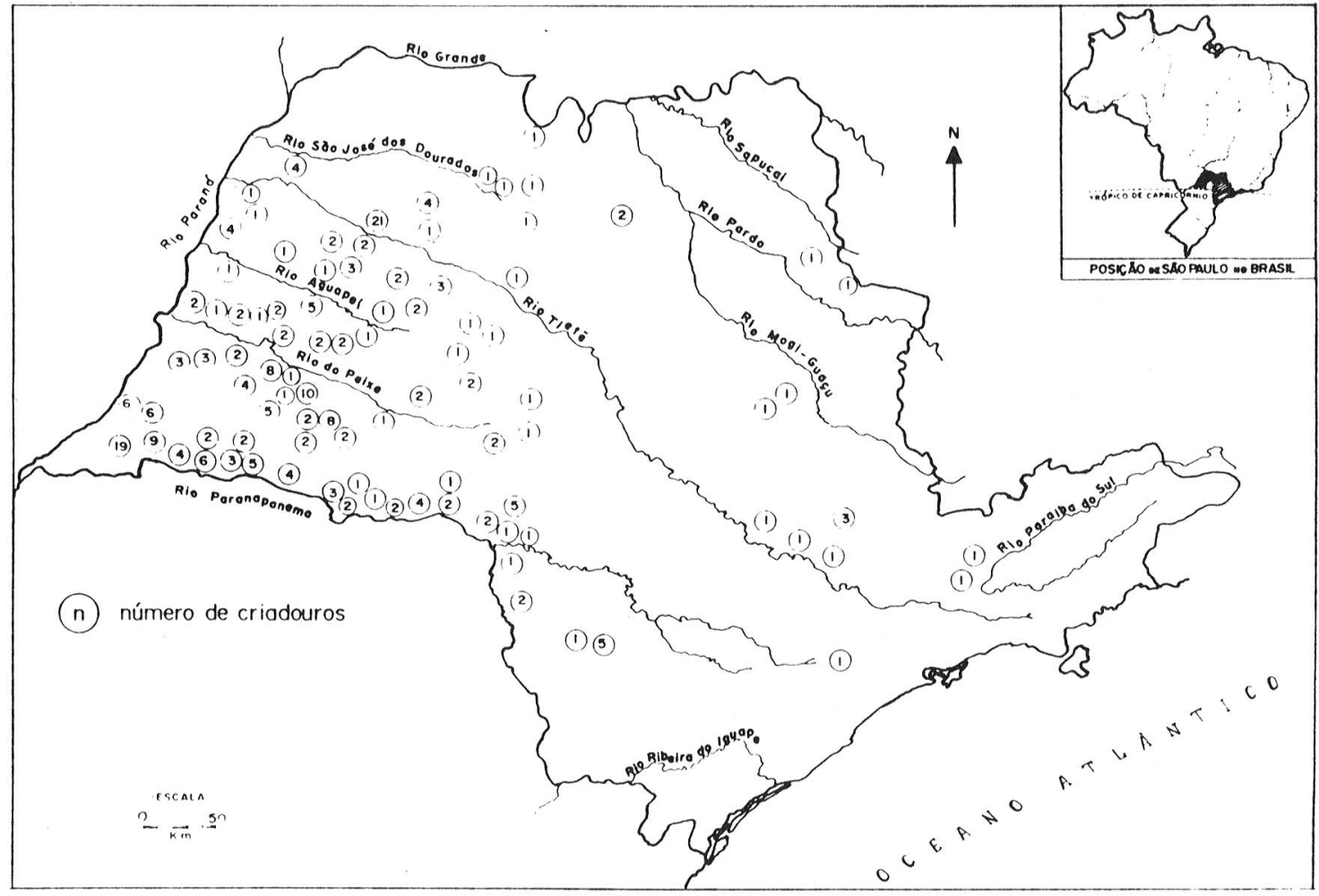

Fig.2 - Localização dos criadouros de Biomphalaria occidentalis descobertos por municipio do Estado de São Paulo (Brasil) de setembro de 1981 a março de 1986.

do, Anhumas, Braúna, Estrela do Norte, Guararapes, Indiana, José Bonifácio, Junqueirópolis, Lucélia, Marabá Paulista, Mariápolis, Martinópolis, Mirante do Paranapanema, Monte Castelo, Narandiba, Nova Luzitânia, Ocauçu, Ouro Verde, Pirajuí, Pirapozinho, Pirassununga, Presidente Bernardes, Presidente Prudente, Presidente Venceslau, Quatá, Quintana, Santo Espedito, São José do Rio Preto, Taiúba, Tabaraí, Teodoro Sampaio e Valparaíso). Em outros dez municípios relacionados com $B$. tenagophila por Piza e col. ${ }^{8}$ (Araçatuba, Boracéia, Campinas, Gastão Vidigal, Mococa, Penápolis, Piracicaba, Rubiácea, Santa Isabel e São Carlos) configurou-se a ocorrência simultânea de $B$. occidentalis. O encontro de $B$. tenagophila, pela primeira vez em 75 municípios, consubstancia maior abrangência do presente inquérito, mesmo que não fosse possível a confirmação da existência de $B$. tenagophila e/ou $B$. occidentalis nos municípios de Adamantina, Aguaí, Agudos, Alto Alegre, Amparo, Anhembi, Araraquara, Barbosa, Birigui, Boituva, Bragança Paulista, Caiabu, Coroados, Corumbataí, Cunha, Dois Córregos, Guará, Herculândia, Iacanga, Ibitinga, Ilha Bela, Inúbia Paulista, Itajú, Itupeva, Ituverava, Jaú, João Ramalho, Lagoinha, Lusiânia, Lutecia, Ma- caubal, Oscar Bressane, Pacaembu, Pardinho, Piacatu, Pinhalzinho, Piracaia, Piratininga, Platina, Rinópolis, Sagres, Santana da Ponte Pensa, Santa Mercedes, Santo Antônio da Posse, Santópolis do Aguapeí, São João do Pau! d'Alho, Tupi Paulista, Tariúba e Várzea Paulista (49 municípios) relacionados na "Carta Planorbídica do Estado de São Paulo"8.

Considerando o número de indivíduos, criadouros e área colonizada pelas duas espécies, é nítida a melhor adaptação de $B$. tenagophila às condiçð̃es dos ambientes límnicos paulistas, visto que a espécie é mais abundante. Associando-se a disposição territorial dos criadouros de $B$. tenagophila com a situação epidemiológica apresentada para a esquistossomose ${ }^{10} \mathrm{e}$ os dados demográficos disponíveis ${ }^{1,9}$, fica evidente que os criadouros da espécie aglomeram-se junto às áreas mais urbanizadas e/ou industrializadas do Estado, instaladas nas bacias do Tietê (Alto e Médio), Vale do Paraíba e litoral, que paralelamente são tidas como áreas endêmicas para Schistosoma mansoni. Afora estas áreas a esquistossomose está instalada no Vale do Ribeira, Município de Bebedouro e Paranapanema Médio. Nesta última área, a doença é veiculada por B. glabrata (Say, 1818). A CETESB ${ }^{2}$ e - $\mathrm{DAEE}^{3}$ atestam que as zonas citadas possuem 
os niveis de poluição hídrica mais elevados de São Paulo, de onde se pode aventar a hipótese que $B$. tenagophila seja bastante resistente às alteraçoes ambientais promovidas pela ocupação humana. Assim facilitado o convívio nas proximidades do homem, sobrepujados os demais fatores limitantes, justificar-se-ia a importância assumida por esse transmissor da endemia entre nós, mesmo não sendo aquele mais suscetível experimentalmente. A abundância de $B$. tenagophila somada à capacidade de integração às condições ecológicas solicitadas no ciclo biológico de $S$. mansoni formam um elo fundamental na manutenção da endemia. Em oposição ao exposto para $B$. tenagophila, $B$. occidentalis manifestou preferência pelos ambientes localizados em regiōes menos poluídas e com o desenvolvimento econômico voltado sobremaneira para a agropecuária (setor oeste do Estado). A respeito do significado epidemiológico de $\boldsymbol{B}$. occidentalis, a inexistência de autoctonia nas áreas habitadas exclusivamente pela espécie, parece confirmar as observações de Paraense e Corrêas, traduzindo a possível inadequação deste planorbídeo com as raças de $S$. mansoni circulantes em São Paulo. Contudo é imprescindível a realização de maiores estudos a respeito das interações parasito $/ \bar{B}$. occidentalis, de vez que na natureza a espécie não está submetida às condições de contaminação sofridas por $B$. tenagophila.

Da simpatria verificada entre $B$. tenagophila e $B$. occidentalis, sabe-se que este evento biogeográfico ocorre com outras espécies de inte- resse sanitário, tornando importante algumas considerações sobre o fenômeno. A distribuição apresentada por Teles e Vaz ${ }^{12,13}$, para os demais hospedeiros de $S$. mansoni, permite a identificação da simpatria entre $S$. glabrata (Say, 1818) e B. tenagophila (Cerquilho, Fartura, Ourinhos, Porto Feliz, Salto Grande, Santa Cruz do Rio Pardo e São Paulo) e entre B. tenagophila e B. straminea (Dunker, 1848) (Bananal, Barra Bonita, Botucatu, Campinas, Castilho, Cruzeiro, Igaratá, Registro, Ribeirão Preto, Salto Grande, Santa Isabel e Taubaté). Teles" ${ }^{11}$ constatou que a simpatria ocasiona a coexistência interespecífica em várias localidades, sugerindo uma investigação apurada dos casos autóctones descobertos nos municípios assim colonizados, bem como recomenda a manutenção de um sistema de vigilância rigoroso, lembrando que certas áreas, com a sobreposição de populações de espécies hospedeiras, são endêmicas para a esquistossomose.

Do ponto de vista geral, a distribuição geográfica de $B$. tenagophila denota que a sobrevivência em condições propícias ao ciclo de $S$. mansoni compensa as dificuldades de interação hospedeiro/parasito, contribuindo para a permanência de regiões endêmicas de considerável extensão. Ainda no perfil epidemiológico da endemia, o convívio acentuado de $B$. tenagophila nas proximidades do homem, sem dúvida é um condicionante revelante para a instalação definitiva da parasitose nos ambientes periurbanos, sendo que esse contexto solicita mudanças nos programas de controle.

TELES, H.M.S. [Distribution of Biomphalaria tenagophila and B. occidentalis in S. Paulo State, Brazil]. Rev. Saúde públ., S. Paulo, 23: 244-53, 1989.

ABSTRACT: The geographical distribution of Biomphalaria tenagophila (d'Orbigny, 1835) and B. occidentalis Paraense, 1981 in S. Paulo State, Brazil, is described. The first species being the most important intermediate host of Schistosoma mansoni Sambon, 1907. The second species is unsusceptible to transmission. The two species inhabit the limnic environments of great areas of S. Paulo, occasionally in simpatria. The 3,160 samples of mollusks collected between September 1981 and March 1986 were examined. B. tenagophila were identified in 1,062 of these samples from 203 municipalities and $B$. occidentalis in 255 samples from 97 municipalities. Biogeographical circunstances related to the distribution of the planorbids species are commented on.

KEYWORDS: Biomphalaria tenagophila, geographical distribution. Biomphalaria occidentalis, geographical distribution. Schistosomiasis, incidence. Ecology, vectors.

\section{REFERENCIAS BIBLIOGRÁFICAS}

\section{ANUÁRIO ESTATÍSTICO DO ESTADO DE SÃO PAULO: 1985. (Fundação SEADE) São Paulo, 1986.}

2. COMPANHIA TECNOLÓGICA DE SANEAMENTO AMBIENTAL (CETESB). Qualidade das águas interiores do Estado de São Paulo. São Paulo, 1984. 3. DEPARTAMENTO DE ÁGUAS E ENERGIA ELÉTRICA (DAEE). Balanço hídrico do Estado de Săo Paulo. Aguas e Energia Elétrica, 12:18-27, 1987. 
4. PARAENSE, W.L. Biomphalaria occidentalis sp.n. from South America (Mollusca, Basommatophora, Pulmonata). Mem. Inst. Oswaldo Cruz, Rio de Janeiro, 76:199-211, 1981.

5. PARAENSE, W.L. \& CORREA, L.R. Unsusceptibility of Biomphalaria occidentalis to infection with a strain of Schistosoma mansoni. Mem. Inst. Oswaldo Cruz, Rio de Janeiro, 77:55-8, 1982.

6. PARAENSE, W.L. \& DESLANDES, N. Observations on the morphology of Australorbis nigricans. Mem. Inst. Oswaldo Cruz, Rio de Janeiro, 53:121-34, 1955.

7. PARAENSE, W.L. \& DESLANDES, N. Australorbis nigricans as the transmitter of schistosomiasis in Santos, State of S. Paulo. Rev. bras. Malar., 8:235-45, 1956.

8. PIZA, J. de T.; RAMOS, A. da S.; MORAES, L.V. de C.; CORRÊA, R. de R.; TAKAKU, L.; PINTO, A.C. de M. Carta planorbldica do Estado de São Paulo. São Paulo, Secretaria de Estado da Saúde, s.d.

9. SECRETARIA DE ECONOMIA E PLANEJAMENTO DO ESTADO. Estado de São Paulo: Diagnóstico. São Paulo, 1973.
10. SUPERINTENDÊNCIA DE CONTROLE DE ENDEMIAS (SUCEN). Situação da esquistossomose no Estado de São Paulo. São Paulo, Secretaria de Estado da Saúde, 1982.

11. TELES, H.M.S. Aspectos ecológicos de Biomphalaria Preston, 1910 (Basommatophora, Planorbidae) no Estado de São Paulo, Brasil. I - Sintopia. Cienc. Cult., 40:374-9, 1988.

12. TELES, H.M.S. \& VAZ, J.F. Distribuição de Biomphalaria glabrata (Say, 1818) (Pulmonata, Planorbidae) no Estado de São Paulo, Brasil. Rev. Saúde públ., S. Paulo, 21:508-12, 1987.

13. TELES, H.M.S. \& VAZ, J.F. Distribuiçâo de Biomphalaria straminea (Dunker, 1848) (Pulmonata, Planorbidae) no Estado de São Paulo, Brasil. Cienc. Cult., 40:173-6, 1988.
Recebido para publicação em 9/9/88. Reapresentado em 16/2/89.

Aprovado para publicação em $21 / 2 / 89$. 


\section{ANEXO}

Exemplares e criadouros de B. tenagophila e B. occidentalis pesquisados em municípios do Estado de Sāo Paulo (Brasil), 1981-1986.

\begin{tabular}{|c|c|c|c|c|}
\hline \multirow{2}{*}{ Município } & \multicolumn{2}{|c|}{ B. tenagophila } & \multicolumn{2}{|c|}{ B. occidentalis } \\
\hline & Exemplares & Criadouros & Exemplares & Criadouros \\
\hline Alfredo Marcondes * & & & 127 & 1 \\
\hline Alvares Machado* & & & 310 & 5 \\
\hline Alvaro de Carvalho* & 23 & 1 & & \\
\hline Americana* & 120 & 6 & & \\
\hline Andradina & & & 1 & 1 \\
\hline Anhembi & 310 & 8 & & \\
\hline Anhumas* & & & 151 & 1 \\
\hline Aparecida* & 964 & 12 & & \\
\hline Apiaí* & 57 & 5 & & \\
\hline Araçatuba*+ & 1325 & 14 & 475 & 21 \\
\hline Araçoiaba da Serra & 72 & 1 & & \\
\hline Araras* & 199 & 2 & & \\
\hline Arujạ & 543 & 11 & & \\
\hline Assis & & & 53 & 1 \\
\hline Avanhandava* & 45 & 1 & & \\
\hline Bananal* & 876 & 15 & & \\
\hline Bariri & 93 & 2 & & \\
\hline Barra Bonita* & 251 & 4 & & \\
\hline Barueri* & 658 & 8 & & \\
\hline Bauru* & 239 & 4 & & \\
\hline Bebedouro & 350 & 6 & & \\
\hline Bento de Abreu & & & 12 & 1 \\
\hline Biritiba-Mirim & 10 & 1 & & \\
\hline Bom Jesus dos Perdões & 36 & 1 & & \\
\hline Boracéia *+ & 42 & 1 & 68 & 1 \\
\hline Botucatu* & 1 & 1 & & \\
\hline Braúna* & & & 190 & 2 \\
\hline Brodosqui & 68 & 1 & & \\
\hline Buri & 12 & 1 & & \\
\hline Buritama & & & 11 & 1 \\
\hline Cabreúva* & 383 & 6 & & \\
\hline Caçapava* & 5202 & 23 & & \\
\hline Cachoeira Paulista* & 223 & 6 & & \\
\hline Cafelândia & 44 & 3 & & \\
\hline Caieiras & 117 & 3 & & \\
\hline Caiuá + & 88 & 1 & 28 & 3 \\
\hline Cajamar & 483 & 8 & & \\
\hline Cajuru & & & 310 & 1 \\
\hline Campinas*+ & 845 & 36 & 72 & 3 \\
\hline Campo Limpo Paulista* & 11 & 1 & & \\
\hline Cananéia & 16 & 1 & & \\
\hline Cânđido Mota & & & 12 & 2 \\
\hline Capivari + & 70 & 1 & 20 & 1 \\
\hline Caraguatatuba & 800 & 11 & & \\
\hline Carapicu iba* & 251 & 5 & & \\
\hline Castilhot & 6 & 1 & 35 & 4 \\
\hline Cerquilho & 139 & 4 & & \\
\hline Charqueada & 43 & 2 & & \\
\hline Chavantes + & 18 & 1 & 33 & 1 \\
\hline Conchas & 601 & 7 & & \\
\hline Cordeirópolis* & 72 & 1 & & \\
\hline Cosmópolis & 40 & 1 & & \\
\hline Cruzália & & & 195 & 3 \\
\hline Cruzeiro* & 60 & 2 & & \\
\hline Cubatão* & 223 & 5 & & \\
\hline Descalvado + & 7 & 1 & 10 & 1 \\
\hline Diadema* & 517 & 7 & & \\
\hline Dracena & & & 194 & 2 \\
\hline Eldorado* & 643 & 32 & & \\
\hline Elias Fausto & 32 & 1 & & \\
\hline Embu * & 94 & 2 & & \\
\hline Embu-Guaçu & 245 & 2 & & \\
\hline
\end{tabular}




\begin{tabular}{|c|c|c|c|c|}
\hline \multirow{2}{*}{ Município } & \multicolumn{2}{|c|}{ B. tenagophila } & \multicolumn{2}{|c|}{ B. occidentalis } \\
\hline & Exemplares & Criadoutos & Exemplares & Criadouros \\
\hline Espírito Santo do Pinhal & 52 & 1 & & \\
\hline Estrela do Norte* & & & 139 & 2 \\
\hline Fartura + & 35 & 1 & 51 & 2 \\
\hline Ferraz de Vasconcelos & 124 & 2 & & \\
\hline Flora Rica* & & & 34 & 2 \\
\hline Flórida Paulista & & & 422 & 2 \\
\hline Flor ínea & & & 38 & 2 \\
\hline Francisco Morato & 58 & 1 & & \\
\hline Franco da Rocha & 145 & 1 & & \\
\hline Gabriel Monteiro & & & 60 & 1 \\
\hline Gália + & 35 & 1 & 43 & 1 \\
\hline Garça* & 48 & 3 & & \\
\hline Gastão Vidigal*+ & 4 & 1 & 20 & 4 \\
\hline Getulina + & 90 & 3 & 47 & 1 \\
\hline Glicério* & 138 & 2 & & \\
\hline Guaiçara & & & 32 & 1 \\
\hline Guaimbê & 94 & 2 & & \\
\hline Guaranta** & 7 & 1 & & \\
\hline Guararapes* & & & 171 & 2 \\
\hline Guararema* & 1923 & 13 & & \\
\hline Guarantinguetá* & 93 & 5 & & \\
\hline Guarujá* & 528 & 10 & & \\
\hline Guarulhos* & 1401 & 16 & & \\
\hline Iacri & 36 & 1 & & \\
\hline Ibaté & 36 & 1 & & \\
\hline Ibiúna + & 323 & 6 & 8 & 1 \\
\hline Icém & & & 2 & 1 \\
\hline lepế & & & 85 & 4 \\
\hline Igaraçu do Tietêt* & 961 & 3 & & \\
\hline Igaratá & & & 20 & 1 \\
\hline Iguape* & 1003 & 31 & & \\
\hline Indaiatuba + & 112 & 3 & 2 & 1 \\
\hline Indiana* & & & 169 & 2 \\
\hline Ipauçu & & & 3 & 1 \\
\hline Iporanga & 120 & 6 & & \\
\hline Iracemápolis* & 56 & 1 & & \\
\hline Irapuru & & & 82 & 2 \\
\hline Itaí & & & 11 & 1 \\
\hline Itanhaém * & 522 & 7 & & \\
\hline Itapecerica da Serra* & 301 & 7 & & \\
\hline Itapetininga & 46 & 1 & & \\
\hline Itapevi* & 914 & 11 & & \\
\hline Itapira* & 256 & 2 & & \\
\hline Itaporanga & 72 & 2 & & \\
\hline Itapuí $i^{*}$ & 26 & 1 & & \\
\hline Itaquaquecetuba* & 879 & 17 & & \\
\hline Itariri* ${ }^{*}$ & 702 & 15 & & \\
\hline Itatiba & 11 & 1 & & \\
\hline Itú* & 1101 & 21 & & \\
\hline Jaboticabal & 20 & 1 & & \\
\hline Jacareí ${ }^{*}$ & 763 & 10 & & \\
\hline Jacupiranga * & 202 & 15 & & \\
\hline Jaguariúna & 10 & 1 & & \\
\hline Jambeiro* & 232 & 2 & & \\
\hline Jandira & 36 & 2 & & \\
\hline José Bonifácio* & & & 22 & 1 \\
\hline Júlio Mesquita* & 51 & 2 & & \\
\hline Jundia ${ }^{*}{ }^{*}$ & 57 & 3 & & \\
\hline Junqueirópolis* & & & 29 & 1 \\
\hline Juquiá* & 291 & 12 & & \\
\hline Juquitiba & 40 & 1 & & \\
\hline Laranjal Paulista* & 135 & $i$ & & \\
\hline Leme* & 76 & 1 & & \\
\hline Lençóis Paulista* & 28 & j & & \\
\hline Limeira* & 90 & 3 & & \\
\hline
\end{tabular}




\begin{tabular}{|c|c|c|c|c|}
\hline \multirow{2}{*}{ Município } & \multicolumn{2}{|c|}{ B. tenagophila } & \multicolumn{2}{|c|}{ B. occidentalis } \\
\hline & Exemplares & Criadouros & Exemplares & Criadouros \\
\hline Lins*+ & 211 & 4 & 25 & 1 \\
\hline Lorena* & 397 & 4 & & \\
\hline Louveira* & 45 & 3 & & \\
\hline Lucélia* & & & 29 & 2 \\
\hline Macatuba* & 53 & 1 & & \\
\hline Mairinque ${ }^{*}$ & 283 & 7 & & \\
\hline Mairipora* & 113 & 3 & & \\
\hline Marabá Paulista* & & & 316 & 6 \\
\hline Maracaí & & & 97 & 1 \\
\hline Mariápolis* & & & 126 & 2 \\
\hline Marília *+ & 235 & 5 & 37 & 2 \\
\hline Marinópolis & & & 4 & 1 \\
\hline Martinópolis* & & & 1180 & 8 \\
\hline Mauá* & 747 & 6 & & \\
\hline Mineiros do Tietê & 57 & 1 & & \\
\hline Miracatu* & 365 & 11 & & \\
\hline Mirandópolis & & & 10 & 1 \\
\hline Mirante do Paranapanema* & & & 193 & 9 \\
\hline Mirassol & & & 1 & 1 \\
\hline Mococa*+ & 36 & 1 & 93 & 1 \\
\hline Mogi das Cruzes* & 860 & 11 & & \\
\hline Mogi-Guaçu & 80 & 1 & & \\
\hline Mogi-Mirim & 72 & 1 & & \\
\hline Mongaguá* & 465 & 9 & & \\
\hline Monte Alto & 123 & 1 & & \\
\hline Monte Aprazível & & & 3 & 1 \\
\hline Monte Castelo* & & & 17 & 1 \\
\hline Mante Mor & 147 & 3 & & \\
\hline Narandiba * & & & 364 & 3 \\
\hline Neves Paulista & & & 7 & 1 \\
\hline Nova Luzitânia * & & & 16 & 1 \\
\hline Nova Odessa* & 73 & 3 & & \\
\hline Ocauçu* & & & 44 & 2 \\
\hline Oriente* & 53 & 1 & & \\
\hline Osasco* & 616 & 15 & & \\
\hline Osvaldo Cruz & & & 143 & 1 \\
\hline Ourinhos + & 170 & 4 & 80 & 2 \\
\hline Ouro Verde* & & & 95 & 1 \\
\hline Palmital & & & 169 & 4 \\
\hline Panorama & & & 53 & 2 \\
\hline Paranapanema & & & 241 & 5 \\
\hline Pariquera Açu* & 9 & 1 & & \\
\hline Paulínia* & 82 & 3 & & \\
\hline Pederneiras* & 725 & 8 & & \\
\hline Pedreira & 29 & 1 & & \\
\hline Pedro de Toledo* & 460 & 21 & & \\
\hline Penápolis*+ & 40 & 1 & 81 & 3 \\
\hline Pereira Barreto & & & 5 & 1 \\
\hline Pereiras* & 156 & 4 & & \\
\hline Peruibe* & 392 & 9 & & \\
\hline Piedade* & 257 & 3 & & \\
\hline Pilar do Sul* & 42 & 1 & & \\
\hline Pindamonhangaba* & 8755 & 17 & & \\
\hline Piquerobi & & & 11 & 2 \\
\hline Piquete* & 750 & 5 & & \\
\hline Piracicaba* & 264 & 9 & 16 & 1 \\
\hline Piraju & 49 & 1 & & \\
\hline Pirajuí* & & & 3 & 1 \\
\hline Pirangi + & 80 & 1 & 73 & 2 \\
\hline Pirapozinho* & & & 602 & 6 \\
\hline Pirassununga * & 35 & 1 & & \\
\hline Poá* & 298 & 7 & & \\
\hline Pompéia * & 113 & 3 & & \\
\hline Porangaba & 77 & 1 & & \\
\hline Porto Feliz * & 398 & 14 & & \\
\hline Praia Grande* & 1303 & 15 & & \\
\hline
\end{tabular}




\begin{tabular}{|c|c|c|c|c|}
\hline \multirow{2}{*}{ Município } & \multicolumn{2}{|c|}{ B. tenagophila } & \multicolumn{2}{|c|}{ B. occidentalis } \\
\hline & Exemplares & Criadouros & Exemplares & Criadouros \\
\hline Presidente Alves* & 62 & 1 & & \\
\hline Presidente Bernardes* & & & 672 & 8 \\
\hline Presidente Epitácio & & & 177 & 6 \\
\hline Presidente Prudente* & & & 2187 & 10 \\
\hline Presidente Venceslau* & & & 111 & 3 \\
\hline Promissão* & 63 & 3 & & \\
\hline Quatá* & & & 30 & 1 \\
\hline Queiroz & 47 & 1 & & \\
\hline Quintana* & & & 45 & 2 \\
\hline Rafard & 50 & 2 & & \\
\hline Rancharia & & & 11 & 2 \\
\hline Redençẫo da Serra* & 55 & 1 & & \\
\hline Regente Feijó & & & 350 & 2 \\
\hline Registro* & 28 & 8 & & \\
\hline Ribeira* & 9 & 2 & & \\
\hline Ribeirão Pires* & 824 & 9 & & \\
\hline Ribeirão Preto* & 28 & 1 & & \\
\hline Ribeirão do Sul & & & 68 & 1 \\
\hline Rincão* & 78 & 1 & & \\
\hline Riversul & 83 & 1 & & \\
\hline Rio Claro* & 108 & 2 & & \\
\hline Rio Grande da Serra* & 297 & 4 & & \\
\hline Roseira* & 1259 & 21 & & \\
\hline Rubiácea *+ & 140 & 3 & 205 & 4 \\
\hline Salesópolis & 463 & 9 & & \\
\hline Salmorão & & & 9 & 1 \\
\hline Salto* & 832 & 9 & & \\
\hline Salto Grande + & 34 & 1 & 76 & 2 \\
\hline Salto de Pirapora & 136 & 3 & & \\
\hline Sandovalina & & & 238 & 4 \\
\hline Santa Bárbara do Oeste & 145 & 3 & & \\
\hline Santa Cruz das Palmeiras & 150 & 1 & & \\
\hline Santa Cruz do Rio Pardo + & 93 & 2 & 161 & 5 \\
\hline Santa Gertrudes* & 7 & 1 & & \\
\hline Santa Isabel ${ }^{*+}$ & 197 & 3 & 14 & 1 \\
\hline Santa Lúcia & 35 & 1 & & \\
\hline Santana do Parnaiba* & 107 & 3 & & \\
\hline Santo Anastácio & & & 405 & 4 \\
\hline Santo André * & 254 & 4 & & \\
\hline Santo Expedito* & & & 20 & 1 \\
\hline Santos* & 648 & 13 & & \\
\hline São Bernardo do Campo* & 338 & 5 & & \\
\hline São Caetano do Sul* ${ }^{*}$ & 523 & 4 & & \\
\hline São Carlos*+ & 148 & 1 & 35 & 1 \\
\hline São José dos Campos* & 7969 & 31 & & \\
\hline São José do Rio Pardo* & 119 & 4 & & \\
\hline São José do Rio Preto* & & & 20 & 1 \\
\hline São Luiz do Paraitinga* & 36 & 1 & & \\
\hline São Manuel & 230 & 3 & & \\
\hline São Miguel Arcanjo * & 20 & 1 & & \\
\hline São Paulo * & 2872 & 10 & & \\
\hline São Pedro & 62 & 1 & & \\
\hline São Roque* & 228 & 5 & & \\
\hline São Sebastião & 1455 & 7 & & \\
\hline São Simão & 1 & 1 & & \\
\hline São Vicente * & 127 & 5 & & \\
\hline Sarapuí & 1 & 1 & & \\
\hline Serrana* & 69 & 3 & & \\
\hline Sete Barras* & 69 & 5 & & \\
\hline Silveiras & 2 & 1 & & \\
\hline Sorocaba* & 317 & 12 & & \\
\hline Sumaré* & 58 & 3 & & \\
\hline Suzano* & 29 & 1 & & \\
\hline Taboão da Serra & 95 & 2 & & \\
\hline Taciba* & & & 391 & 5 \\
\hline
\end{tabular}




\begin{tabular}{|c|c|c|c|c|}
\hline \multirow{2}{*}{ Município } & \multicolumn{2}{|c|}{ B. tenagophila } & \multicolumn{2}{|c|}{ B. occidentalis } \\
\hline & Exemplares & Criadouros & Exemplares & Criadouros \\
\hline Taguaí & 8 & 1 & & \\
\hline Tarabaí* & & & 130 & 2 \\
\hline Taubaté* & 4007 & 35 & & \\
\hline Teodoro Sampaio* & & & 646 & 19 \\
\hline Tietê * & 394 & 8 & & \\
\hline Timburi & & & 12 & 1 \\
\hline Tremembé* & 3704 & 9 & & \\
\hline Tupa** & 33 & 1 & & \\
\hline Ubatuba* & 3238 & 8 & & \\
\hline Valinhos* & 154 & 4 & & \\
\hline Valparaiso* & & & 15 & 2 \\
\hline Vargem Grande Paulista & 308 & 6 & & \\
\hline Vargem Grande do Sul & 39 & 1 & & \\
\hline Vera Cruz* & 42 & 1 & & \\
\hline Vinhedo & 20 & 1 & & \\
\hline Votorantim & 623 & 12 & & \\
\hline Total & 85.037 & 062 & 13.959 & 255 \\
\hline
\end{tabular}

* B. tenagophila assinalada também por Piza e $\mathrm{col}^{8}$.

+ simpatria 